\title{
Recipes for Men: \\ Manufacturing Makeup and the Politics of Production in 1910s China
}

\author{
by Eugenia Lean*
}

\begin{abstract}
In the first decade of Republican China (1911-49), masculinity was explored in writings on how to manufacture makeup that appeared in women's magazines. Male authors and editors of these writings - some of whom were connoisseurs of technology, some of whom were would-be manufacturers - appropriated the tropes of the domestic and feminine to elevate hands-on work and explore industry and manufacturing as legitimate masculine pursuits. Tapping into time-honored discourses of virtuous productivity in the inner chambers and employing practices of appropriating the woman's voice to promote unorthodox sentiment, these recipes "feminized" production to valorize a new masculine agenda, which included chemistry and manufacturing, for building a new China.
\end{abstract}

In the 1910s, a curious print culture phenomenon appeared in China's urban areas. Journals such as Funü zazhi (Ladies' journal) and Nüzi shijie (Women's world) began to run columns and articles that provided highly detailed, technical information on soap, hair tonic, perfume, and rouge. These columns did not describe how to consume but instead how to produce these items, offering the home as the perfect space for such cosmetic production. In 1915, Funü zazhi ran several such articles in its "Technologies" [xueyi] section. Titles include "A Brief Explanation on Methods for Making Cosmetics" in the January issue, "Method for Making Rouge" in the March issue, and "Method for Producing Cosmetics" in the May issue. ${ }^{1}$ Also in 1915, Nüzi shijie

*Columbia University, 925 IAB MC 3333, 420 West 118th Street, New York, NY 10027; eyl2006@ columbia.edu.

This research was supported by the Charles A. Ryskamp Fellowship from the American Council of Learned Societies, the Taiwan Fellowship from the Ministry of Foreign Affairs and the Center for Chinese Studies, National Central Library, and funding from the Weatherhead East Asia Institute at Columbia University. Thanks to Erika Lorraine Milam, Robert A. Nye, Debbie Coen, Daniel Asen, Liza Lawrence, Alexander Des Forges, Jacob Eyferth, and two anonymous readers for reading drafts of this essay. I would also like to thank participants at the "Masculinities in Science/Sciences of Masculinity" conference, sponsored by the Philadelphia Area Center for History of Science, upon which this volume is based, and the audiences at related talks that I have given at Princeton University; Harvard University; Columbia University; Ohio State University; Triangle East Asia Colloquium, North Carolina; Fudan University, Shanghai; and the Academia Sinica in Taiwan.

${ }^{1}$ Ling Ruizhu, "A Brief Explanation of the Methods to Make Cosmetics," Funü zazhi 1 (January 1915): 15-8; Hui Xia, "Method for Making Rouge," Funü zazhi 1 (March 1915): 15-6; Shen Ruiqing, "Method for Manufacturing Cosmetics," Funü zazhi 1 (May 1915): 18-25.

${ }^{\oplus} 2015$ by The History of Science Society. All rights reserved. 0369-7827/11/2015-0007\$10.00

OSIRIS 2015, $30: 134-157$ 
featured a new column from January to May, "The Warehouse for Cosmetic Production," which appeared regularly under the "Industrial Arts" [gongyi] section. What makes these writings notable is that they deem their detailed technical manufacturing information as highly appropriate for women to apply in the domestic realm. And yet, despite the claim that these were tasteful recipes for women, the production of this discourse was not just for women, but also-if not primarily - by and for men. By employing gendered rhetorical strategies, male authors and editors inflected the discourse of domestic production with moral legitimacy. They sought to "cleanse" the manual work of technology of any problematic class connotation so that it could be reclaimed by new-style urban men, including lettered connoisseurs of technology, amateur scientists, and would-be manufacturers.

A typical example of the gendered portrayal of domestic manufacturing in these writings can be found in the first run of the Nüzi shijie column, "The Warehouse for Cosmetic Production" (hereafter, "The Warehouse"). The piece appeared in the January 1915 issue of this women's magazine and was titled "An Exquisite Method for Manufacturing Hair Oil." The editor of the column, as well as the overall editor of Nüzi shijie in 1915, was Tianxuwosheng (Heaven Bore Me in Vain), the pseudonym for Chen Diexian (1878-1940), a highly influential editor who was also a romance novelist and, later, an industrial captain. In the column that appeared in the February issue, Tianxuwosheng wrote that the first appearance of the column had elicited much interest and a reader by the name of Mme Xi Meng had already sent in a request asking him to divulge more tips. ${ }^{2}$ Highly amenable to this request, Tianxuwosheng provided information on how to produce some of the basic ingredients of hair tonic. Listed in both Chinese and Latin, ${ }^{3}$ these ingredients included:

\begin{tabular}{|c|c|}
\hline $\begin{array}{l}\text { 純粹硫酸 } \\
\text { 檸檬油 }\end{array}$ & $\begin{array}{l}\text { Acidum Sulphruicum [sic] } \\
\text { Oleum Limonis }\end{array}$ \\
\hline $\begin{array}{l}\text { 玫瑰精 } \\
\text { 硼砂 } \\
\text { 橙花水 } \\
\text { 油精 }\end{array}$ & $\begin{array}{l}\text { Spiritus Rosae } \\
\text { Borax } \\
\text { Aqua Aurantii Florum } \\
\text { Spiritus }\end{array}$ \\
\hline $\begin{array}{l}\text { ‥ } \\
\text { 丁香油 } \\
\text { 肉桂油 } \\
\text { 橙皮油 } \\
\text { 屈里設林 }\end{array}$ & $\begin{array}{l}\text { Nelkeuöl [sic] } \\
\text { Oleum Cinnamomi } \\
\text { Oleum Aurantii Corticis } \\
\text { Glycerin }\end{array}$ \\
\hline $\begin{array}{l}\text { 白米澱粉 } \\
\text { 白檀油 }\end{array}$ & $\begin{array}{l}{[\text { Rice Starch] }} \\
\text { Oleum Santali }\end{array}$ \\
\hline
\end{tabular}

2 Tianxuwosheng, "Huazhuangpin zhizao ku,” Nüzi shijie 2 (February 1915): 3.

${ }^{3}$ Note that a few ingredients are not listed in Latin. Glycerin is English, and Nelkeuöl [recte Nelkenöl] is the German word for oil of cloves.

4 Tianxuwosheng, "Huazhuangpin zhizao ku" (cit. n. 2), 4. These ingredients are better known as sulfuric acid, oil of lemon, the essence of roses (i.e., the scent of roses), borax or hydrated sodium borate, orange flower water, alcohol, oil of cloves, oil of cinnamon, oil of orange peel, sugar alcohol, rice starch, and oil of sandalwood. 
Many of the items, he explained, could be purchased in Shanghai's pharmacies, but since spiritus rosae was particularly expensive, he wanted to make its recipe readily available. His instructions read:

Extract the fragrance of fresh flowers, and attach it onto something solid, so that it lasts and does not disappear. There are many ways of doing this. One can use a method for suction; the method for squeezing, the method for steaming, the method for soaking. None of these are as ideal as the method for absorption. To make spiritus rosae, use the method for absorption. ${ }^{5}$

What follows is a detailed and technical description of how to achieve this method for absorption at home. The tools, instruments, and materials needed include bottles, tubes, alcohol burners, hydrochloric acid, and no less than five pounds of marble.

A simple review of the first two entries of "The Warehouse" column shows how these writings struck a curious balance between presenting highly technical detail and a practical "how-to" sensibility. Moreover, this column presented the information as appropriate for household use by women. Household manufacturing and production were thus elevated over the consumption of mass-produced items from new-style pharmacies, and experimentation and lab work were promoted as appropriate for the home. Finally, the editor seemed driven by a mission to unveil heretofore secret recipes, formulas, and how-to knowledge in the new urban press. By doing so, he sought to make such information available to an engaged reading public, ideally made up of female readers like Mme Xi Meng. ${ }^{6}$ The presentation of manufacturing and production knowledge as appropriate for women and located in the domestic arena was explicit.

And yet participants in this discourse included men, ranging from male connoisseurs of technology to dabblers in chemistry and from cosmopolitan lettered elites to budding industrialists. Often closely linked to the rising industrial sector in which advances in chemistry and manufacturing were promoted as necessary for the betterment of Chinese society, male authors and editors were key producers of this discourse on virtuous domestic production. They rendered the how-to pieces in reformist women's periodicals as sites where experiential engagement with chemistry and manufacturing was promoted as crucial in strengthening China, as well as a sign of good taste and bearing. In a period when men were obsessively writing about the plight of women in Chinese society and promoting models of new womanhood, these instructive pieces, which were also written and compiled by men, featured idealized visions of manufacturing women in the inner chamber in order to promote an agenda for men that wedded modern chemistry, technology, and hygienic domesticity. ${ }^{7}$ As we will see, they drew on a long history of male literati appropriating the more ethically powerful woman's voice to levy criticism against the political orthodoxy and promote alternative male personae. By 1915, a transitional period when masculinity was in flux, the pure "inner chambers" were deemed a site where virtuous agendas

\footnotetext{
5 Ibid., 6.

${ }^{6}$ Some writers claimed to be women, and I will discuss the significance of the gender of both writers and consumers of such writings below.

${ }^{7}$ A great deal of work has been done on the male-dominated discourse of New Womanhood in early twentieth-century China, and how such a discourse on women served male interests to define themselves and their masculine agendas of reforming the family, society, and the Chinese nation. See, e.g., Susan Glosser, Chinese Visions of Family and State, 1915-1953 (Berkeley and Los Angeles, 2003).
} 
such as building industry, strengthening the nation, and laying a strong manufacturing base were articulated as alternatives to the traditional route of government service or the contemporary option of republican politics, which were mired in paralysis and dysfunction. Such a view complicates the more conventional narrative drawn from modern Western experiences in which the masculinization of science and industry marginalized and excluded women in both practice and rhetoric. In this volume, for example, several essays examining the rise of modern science in the United States and Europe provide detailed analyses of the contexts in which forms of technology, science, and related endeavors have been declared manly. ${ }^{8}$ From the perspective of 1915 China, on the other hand, we see that at least in rhetoric, women were identified as the primary agents in the construction of new masculinist agendas.

\section{POLITICAL DISARRAY, KNOWLEDGE PRODUCTION, AND THE REMAKING OF MASCULINITY}

To grasp the full significance of the gendered presentation in these recipes, we need to take into consideration how by the end of the nineteenth century, educated men had become increasingly disenchanted with serving as officials in the imperial bureaucracy or engaging in other traditional activities of China's lettered elite. Weakened by half a century of internal rebellion and Western imperialist aggression, the Qing dynasty (1644-1911) had in the early twentieth century begun to engage in eleventh-hour reforms geared toward saving the moribund dynasty. These reforms had a profound impact on elite strategies of cultural, social, and political reproduction. Most significant was the 1905 dismantling of the examination system, the bureaucratic mechanism long used by the imperial state to recruit bureaucrats and ensure their ideological and institutional loyalty. The institutionalized ties between educated men and the political center were fundamentally severed, and state privileging of the Confucian canon and its moral text-based knowledge came to an abrupt end. The political disenfranchisement of educated Chinese men deepened with the fall of the empire in 1911. The first decade of the new Republic (1911-49) started with great promise but quickly disintegrated into a period of political disarray. The goals of the 1911 revolution - including the establishment of a legitimate constitution and parliamentary government-were proving elusive. By 1915, China's experiment with republicanism was effectively in shambles when militarist Yuan Shikai threatened to turn China from a republic back into an empire with himself at the helm. In a context in which "traditional" modes of Confucian knowledge and long-vaunted careers in the imperial bureaucracy were no longer feasible, many of China's lettered men started to explore new regimes of knowledge and experiment with new social and occupational roles, as well as reconsider fundamentally what it meant to be an elite man. With the chaos of republican politics threatening national strength, especially in the north, these men often traveled to China's new treaty ports, where modern print industries,

\footnotetext{
${ }^{8}$ See esp. the essays by Michael S. Reidy on late Victorian male alpinists ("Mountaineering, Masculinity, and the Male Body in Mid-Victorian Britain"), Alexandra Rutherford on mid-twentieth-century American psychology ("Maintaining Masculinity in Mid-Twentieth-Century American Psychology: Edwin Boring, Scientific Eminence, and the 'Woman Problem"'), Erika Lorraine Milam on the gendering of human nature in the 1960s and 1970s ("Men in Groups: Anthropology and Aggression, 1965-84"), and Nathan Ensmenger on gender competition in the professionalization of computer programming in the United States ("'Beards, Sandals, and Other Signs of Rugged Individualism”: Masculine Culture within the Computing Professions"), all in this volume.
} 
growing consumer cultures, and mercantile and light manufacturing were flourishing. ${ }^{9}$ In this new context, industry and manufacturing, along with the once taboo realm of commerce, increasingly became legitimate ways of strengthening Chinese society and nation outside of the political arena.

Writings such as those found in "The Warehouse" helped promote chemistry, industrial technology, and manufacturing knowledge as foundational pillars of national strength. It was far from "natural" for well-educated men to turn toward production and manufacturing. The literati had long felt a severe distaste for hands-on engagement with things for subsistence or commercial purposes, which, despite the many reforms taking place, persisted into the twentieth century. Suspicion of certain skills and forms of knowledge long associated with toiling artisans and profit-pursuing merchants remained strong among the well educated. To change such entrenched views, publications highlighted new fields of knowledge, most prominently, chemistry and physics, which had experienced advances in nineteenth-century Europe's second industrial revolution and fueled industrial development in Europe, the United States, and, after the 1870s, Japan. They also incorporated insights from related fields, like industrial technology and manufacturing. The writings also strongly emphasized the making of things (zhizuo or zhizao), demanded physical engagement with material objects, and exhorted experimentation and experiential knowledge. These skills and virtues-long the purview of the artisan class-were now identified as appropriate for the urban educated elite.

To mobilize support for this agenda of redefining elite masculine endeavors, writers of these recipes adopted the woman's voice as an effective vehicle with which to present the information on manufacturing and chemistry. To "domesticate" the technical know-how, editors and writers of these pieces — who were primarily men-portrayed technical knowledge and manufacturing practice as feminine and located production squarely in the domestic realm. By promoting the manufacture of goods such as cosmetics and beauty items, these articles not only tapped into a growing global market that revolved around the care of the self and the cultivation of health and beauty but also drew from globally circulating discourses that endorsed the idea that the health of nations depended on the health of their national citizens. ${ }^{10}$ In a context where China was subject to unfair treaties in the hands of imperialist powers and had earned the reputation of being the "Sick Man of Asia," advancing the health and beauty of its female citizens gained symbolic significance. ${ }^{11}$

To understand fully why editors like Tianxuwosheng decided to appropriate the female voice, we also need to keep in mind the longer historical trend of gendering virtuous production as feminine in late imperial China. In the late imperial period,

\footnotetext{
${ }^{9}$ Disenfranchised literati had already started to find new opportunities in treaty ports in the latter part of the nineteenth century, when moribund court politics and widespread factionalism and corruption drove many away from Beijing. For more on how literati translated their cultural skills into profit in the new circles of print, entertainment, and leisure in cities such as Shanghai, see, e.g., Christopher Reed, Gutenberg in Shanghai: Chinese Print Capitalism, 1876-1937 (Honolulu, 2004).

${ }_{10}$ See, e.g., Mary Lynn Stewart, For Health and Beauty: Physical Culture for Frenchwomen, 1880s1930 s (Baltimore, 2000), on the physical culture of French women in the late nineteenth and early twentieth centuries, which focused on their health and beauty within the context of the French state's concern for healthy families and the reproductive fitness of the nation. As we see here, in these recipes, the concern for female health and beauty lurked behind the agenda of promoting manufacturing knowledge among progressive readers.

${ }^{11}$ For more on the term "Sick Man of Asia," see the introduction to Ruth Rogaski, Hygienic Modernity: Meanings of Health and Disease in Treaty-Port China (Berkeley and Los Angeles, 2004).
} 
there had been considerably more room for upper-class women to engage in handwork and manufacturing. Francesca Bray identifies a gendered distribution of elite skills in the late imperial period in terms of the concept of qiao (craft, cunning, skill). ${ }^{12}$ Manual qiao was an attainment to which educated men or even farmers never really aspired. Instead, it was a characteristic primarily of male artisans. Yet, as a female attribute, qiao transcended class. Associated with "womanly work," especially in textile production, it functioned to denote a relation to the material world through which women crafted a path to virtue. ${ }^{13}$ The Confucian slogan, "men till and women weave" (nangeng nüzhi) alluded to this gendered economy of qiao, suggesting that virtuous male skill resided in the agricultural arena, while female skill was linked to the production of textiles. In these how-to pieces from the 1910s, the gendered presentation of manufacturing invoked these earlier discourses of Confucian household management and virtuous female production.

There was also a long-standing tradition in Chinese literary history of male literati assuming a woman's sentimental voice, especially when alienated from the political center. As research on the last decades of the Ming dynasty (1368-1644) has shown, in an earlier era of political crisis, disenfranchised literati appropriated the symbolically powerful voices of concubines in their writings to express discontent with orthodox knowledge and politics. ${ }^{14} \mathrm{~A}$ woman's voice was seen as more sentimental, more genuine for expressing inner emotions, such as frustration, pathos, and anger, and hence more effective in articulating criticism of the failure of orthodoxy and statecraft. In the final decades of the Qing, lettered men echoed their late Ming counterparts. The man-of-feeling persona gained currency as a vehicle to legitimize new endeavors and pursuits such as literary projects that included assuming the highly sentimental voices of the effete heroes of popular romance novels, most notably the famous Dream of the Red Chamber. ${ }^{15}$ With the masculinity of China's lettered men in crisis during the fragile years of the early Republic, male editors could also appropriate the female persona to claim a new form of moral authority. In the writings here, editors identified a female subject as the ideal producer, promoted household production of womanly things, and tapped into the morally charged trope of the domestic. They evoked classical discourses on production and the investigation of things to render chemistry, manufacturing, and bodily engagement with production as legitimate alternatives to politics and statecraft for elite men.

In a period when institutions of knowledge production, social occupations, and masculinity were all in flux, the "ownership" of science, technology, and industry was also not yet fixed. As lettered men turned to new forms of knowledge and engaged in new endeavors, they did so before systematic industrialization, the professionalization of occupational organizations related to industry and manufacturing, and the founding

${ }^{12}$ Francesca Bray, Technology and Gender: Fabrics of Power in Late Imperial China (Berkeley and Los Angeles, 1997).

13 To be sure, talented gentry women [cainü] were highly invested in expressing their virtue and class identity through poetry and textual engagement like their male counterparts. Yet female activities such as embroidery, painting, and textile production were considered equally respectable and a crucial sign of female virtue and classical education.

${ }^{14}$ Ellen Widmer, "Xiaoqing's Literary Legacy and the Place of the Woman Writer in Late Imperial China," Late Imperial China 13 (1992): 111-55.

${ }^{15}$ For more on the ritualized role-play based on novels, such as Dream of the Red Chamber, see Catherine Yeh, Shanghai Love: Courtesans, Intellectuals, and Entertainment Culture, 1850-1910 (Seattle, 2006). 
of related modern scientific academic disciplines such as chemistry and physics. As a result, the questions of who owned "science," who was responsible for adapting and producing new knowledge on manufacturing, where such knowledge was to be applied, and for what purposes, were under debate. To be sure, in practice artisanal production and indigenous merchant activities from salt manufacturing to papermaking continued to thrive. ${ }^{16}$ But, intellectuals faced with the Qing state's weakness in the latter part of the nineteenth century started to put indigenous regimes of knowing the natural world and "traditional" forms of technology under harsh scrutiny. In response to this perceived political and technological crisis, an array of Chinese actors had started to adapt new forms of production knowledge and apply them to strategic ends. During the Self-Strengthening Movement (ca. 1861-95), the Qing state had sponsored the establishment of arsenals where Chinese provincial statesmen worked closely with Western missionaries and experts, along with Chinese artisans, to translate and adapt Western technological knowledge. With the express goal of building China's military armaments and national strength, the Self-Strengthening Movement came to an end following China's defeat in the Sino-Japanese War in 1895. The ensuing early Republican state proved far less effective in sponsoring industrial development in a systematic manner. In the absence of strong state action, scholarly societies of the late Qing, and new scientific organizations of the 1910s, such as the Science Society of China (SSC), emerged from this vacuum, taking initial steps toward professionalizing and providing an institutional identity to modern science. ${ }^{17}$ Missionary schools beginning in the first decades of the twentieth century started offering courses on chemistry, engineering, and physics, but it was not until the 1920s that the institutionalization and professionalization of science developed systematically with the creation of academic disciplines in Chinese universities and related professional "fields" more broadly. ${ }^{18}$

If the period was in flux, it was not merely a "transitional" stage in China's inevitable march toward modern industry, a characterization that smacks strongly of teleology. Nor was it an inferior, less substantial engagement with science and manufacturing than similar situations in other periods or places. Rather, we should consider that China in the 1910s represented a time of multiple opportunities and possibilities as industry and manufacturing developed in various informal spaces and sites. Industrial endeavors were not yet firmly established in factories, laboratories, or the research halls of academia but were pursued in locations such as the studios of literati, reading rooms, domestic and private spaces, and the how-to columns in women's magazines emerging in China's burgeoning consumer culture. Statesmen no longer

${ }^{16}$ For work on Chinese salt merchants, see Madeleine Zelin, The Merchants of Zigong: Industrial Enterprise in Early Modern China (New York, 2005). For work on paper makers, see Jacob Eyferth, Eating Rice from Bamboo Roots: The Social History of a Community of Handicraft Papermakers in Rural Sichuan, 1920s-2000 (Cambridge, Mass., 2009).

17 James Reardon-Anderson, The Study of Change: Chemistry in China, 1840-1949 (Cambridge, 1991), 93-101.

${ }^{18}$ For more on the development of modern chemistry education, see ibid., esp. chap. 5. For work on the emergence of the modern field of geology, see Grace Shen, Unearthing the Nation: Modern Geology and Nationalism in Republican China, 1911-1949 (Chicago, 2013). For forensics, see Daniel Asen, "Dead Bodies and Forensic Science: Cultures of Expertise in China, 1800-1949" (PhD diss., Columbia Univ., 2012). The professionalization of science coincided with the rise in the professionalization of modern occupations such as medicine, law, and journalism during the 1920s. See Xiaoqun Xu, Chinese Professionals and the Republican State: The Rise of Professional Associations in Shanghai, 1912-1937 (Cambridge, 2000). 
spearheaded these pursuits as they did during the Self-Strengthening Movement, and academics and professional industrialists did not yet monopolize them as they were to do in later periods. Key players were regional elites, male and female urban connoisseurs, maverick entrepreneurs, and amateur scientists, many of whom appropriated and applied this knowledge and these endeavors in a leisurely manner rather than as academic or professional specialists. Knowledge about chemistry and industry was increasingly commodified, published in commercial journals in burgeoning print markets like Shanghai, where experts of "taste" promoted industrial know-how for selffashioning urban consumers. In such a context, the recipes discussed in this article functioned in multiple ways. Rhetorically they urged readers to develop an interest in scientific know-how, while supplying tips and information for practical application. The pieces could thus appeal to connoisseurs of technology and to urban readers eager to establish their cosmopolitanism. They were also attractive to amateur scientists and would-be manufacturers who sought concrete knowledge that would advance their hands-on endeavors in industry and manufacturing.

\section{THE WOMEN'S PRESS}

Before we turn to the articles themselves, it is worth discussing the nature of China's women's press. The gendering of this knowledge began with the appearance of these pieces in women's press journals. Despite being known as women's journals, early twentieth-century women's press titles offered unique editorial space where both male and female readers could explore new ideas and epistemological configurations. ${ }^{19}$ It is important to appreciate the extent of the mixed-gender nature of these journals in considering the "woman's voice" as a powerful tool in which the modern subjectivities of men and women alike could be expressed. In early twentieth-century China, womanhood had become increasingly politicized as a site for the articulation of modernity. Identities such as the new female student and the modern bourgeois housewife were powerful rhetorical tropes, which any writer, regardless of gender, could employ to dispense information or explore new regimes of knowledge. Male contributors frequently assumed the moniker of "Lady" [nüshi] so-and-so to enjoin male and female readers to be a part of the "women's world." 20

As a particularly lively sector of the commercial press, women's journals quickly came to provide an exciting forum for exploring new ideas and ways of thinking, including information we would now classify as related to the fields of modern science and technology. The journals were hardly uniform, and their exploration of new forms of knowledge assumed different political connotations. Nüzi shijie and Funü zazhi,

${ }^{19}$ For an excellent treatment of the mixed-gender nature of authors and readers of Funü zazhi, see Hsu-Chi Chou, "Yuedu yu shenghuo-Yun Daiying de jiating shenghuo yu 'Funü zazhi' de guanxi" [Reading and lifestyle _ Yun Daiying's family life and its relationship with "The Ladies' Journal"], Si yu yan: Renwen yu shehui kexue zazhi 43 (September 2005): 107-90.

${ }^{20}$ By identifying themselves as female students at a particular school, and/or by referring explicitly to their targeted (female) readers as "comrades in the women's world," several of the writers seemed to signal that they were women by using nüshi 女士 ("Lady" or "Mme"). However, we should be careful not to take such authorial claims of speaking in a woman's voice too literally in every single instance. Lesser-known or unknown male writers often assumed names ending with nüshi in order to have their work published in the women's press. See Jacqueline Nivard, "Women and the Women's Press: The Case of the Ladies' Journal (Funü zazhi) 1915-1931," Republican China 10 (1984): 37-55, on 48. That said, women writers - while in the minority - adopted these same conventions and wielded them effectively to legitimate their growing participation in the public literary realm. 
the two journals that featured these how-to writings, were important women's press titles in early twentieth-century China. Nüzi shijie had a brief run, published from December 1914 to July 1915. In contrast, Funü zazhi was one of the longest-running women's journals. Unlike missionary-produced science magazines of the end of the nineteenth century, neither title exclusively featured writings on science and technology. Founded in December 1914 by Tianxuwosheng, the editor of the "Warehouse" column, Nüzi shijie was actually primarily devoted to poetry and fiction, writings to be consumed by the refined and genteel female [guixiu] reader (fig. 1). Information falling under the categories of industrial arts [gongyi], household [jiating], fine arts [meishu], and hygiene [weisheng] only appeared toward the back of the magazine.

Whereas Nüzi shijie's targeted reader was the genteel female or guixiu, Funü zazhi explicitly identified modern female students as its intended audience and featured progressive opinion pieces and social issue essays or articles [lunshuo]. After an initial set of illustrations and photographs (often of respectable modern women), the leading content section of the journal featured opinion essays, including pieces that dealt with topics such as female education. In the back part of the journal, sections such as technologies [Xueyi], home economics [Jiazheng], fiction, literary selections (literally, "a garden of literature" or Wenyuan), the arts, and other miscellaneous items were found. Articles on how to make cosmetics and toiletries were included in the "technologies" [Xueyi] section, along with other "popular science" articles, including "A brief discussion of daily physics and chemistry," "Method to eliminate stains from cloth," "The way to measure Chinese weights," "Animals' self-defense," and "The consciousness of plants." 21

The way women's journals classified these writings reveals how these pieces sought to prescribe new knowledge and information and, more specifically, redistribute the ownership of technical knowledge and skill from a regime of production once associated with artisans to a more lettered audience. Notably, the how-to writings were not classified under categories of traditional elite knowledge such as poetry and belles lettres, which constituted separate sections of at least the Nüzi shijie. Rather, the magazines classified the writings under different yet related terms, with Nüzi shijie categorizing them as gongyi, or "industrial arts," whereas in Funü zazhi they fell under the category of xueyi, or "technologies." The overlap and fuzziness of the two terms speak to the instability of the categories in the 1910s. ${ }^{22}$ The term gongyi appeared more specifically focused on industrial knowledge of manufacturing through chemical processes, and xueyi suggested a broader subject matter. Nüzi shijie's usage of gongyi more narrowly focuses on forms of knowledge and practices involving the use of original ingredients to make something new, often with chemical processes, such as food recipes or dye making. In contrast, the Funü zazhi's use of xueyi was more expansive and included a range of topics including domestic production of soap, 100 simple cures for common maladies, and an introduction to a Western-style chessboard.

The readership of both Nüzi shijie and Funü zazhi was somewhat exclusive.

${ }^{21}$ Some of these were multi-issue articles, and they are chosen from a review of the first four years of the journal, from 1915 to 1919.

22 These terms started to accrue these meanings in an earlier context of science and technology translation. In the 1895 technological treatise Xixue fuqiang congshu [Collectanea of Western learning and political economy] based on missionary translations of Western technology, technologies such as soap making were classified under the heading of xueyi, which, in turn, was classified under gongyi, or "industrial arts." 

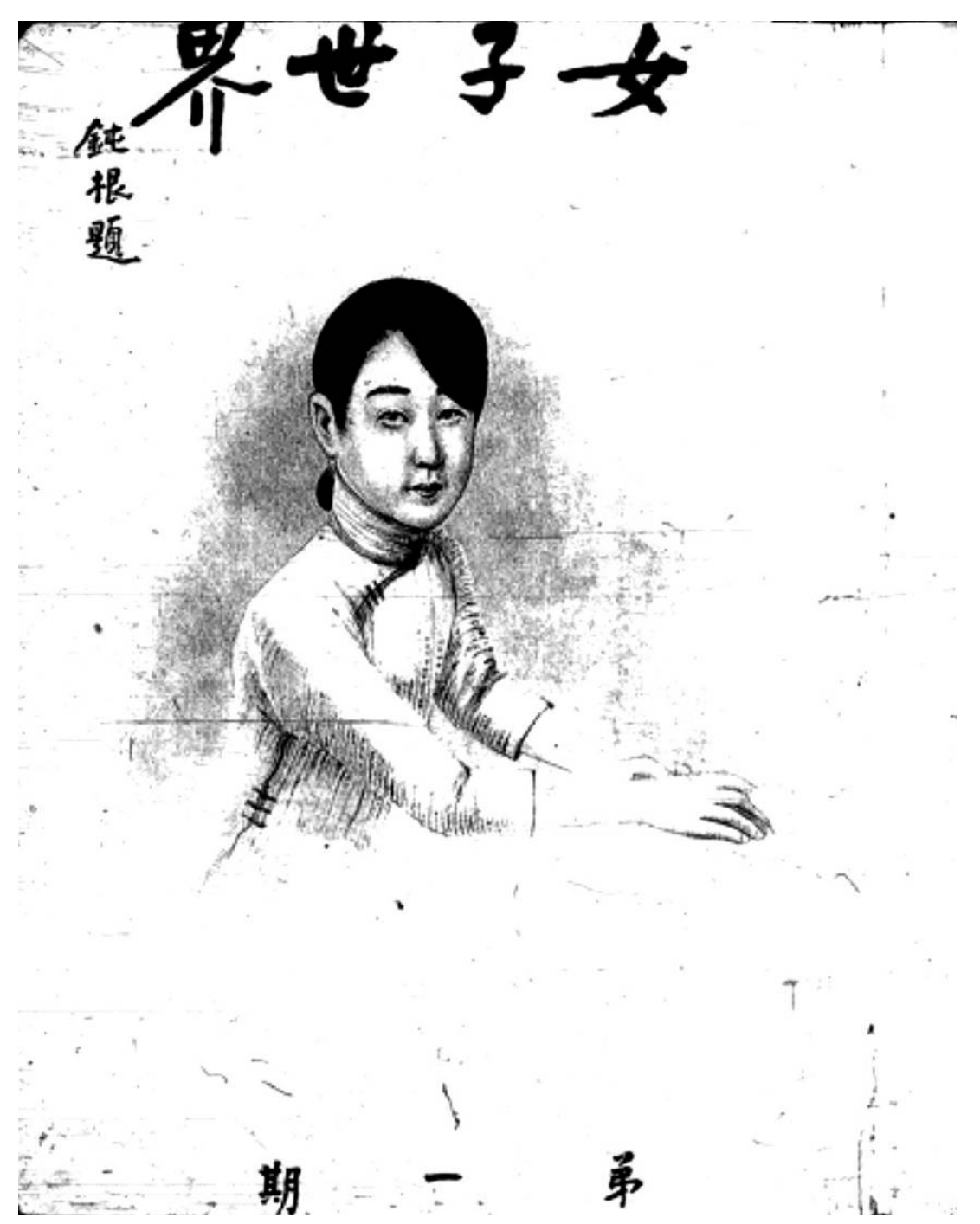

Figure 1. The cover of the January 1915 issue of Nüzi shijie. The cover visually evokes the inner chambers of the guixiu by featuring a well-groomed, respectable woman, posing demurely in a graceful sitting position. On other covers, the woman of the inner chambers is framed by part of a doorway or wall, accompanied in some cases by a cat or a teakettle, items of the household domain.

Whereas the major dailies would reach far more readers in the next few decades, these journals nonetheless had a decent distribution. Literary historian Perry Link estimates that 3,000 copies of the Nüzi shijie were being published and that copies were then shared or read collectively, with an estimated 10,000 readers per issue. ${ }^{23}$ The geographic reach of these journals was also impressive. Examining the letters to

${ }^{23}$ Perry Link, personal communication with Eugenia Lean, 27 March 2006, Princeton University, Princeton, N.J. 
the editor that were sent into a regular column in the Funü zazhi on medical advice that ran from 1929 to 1931, historian Chang Che-chia argues that while the majority of the letters were from Shanghai, Guangzhou, and the Jiangnan area, letters came from as far as Japan and Chongqing. ${ }^{24}$ While the medical column examined by Chang was published later than the Funü zazhi issues I study here, its reach suggests that even in the 1910s, the geographic distribution of the Funü zazhi was not necessarily confined to the Shanghai area.

Articles in these journals were frequently direct, if unattributed, translations of pieces in the Western or Japanese press, or translated modules of texts, recipes, and images taken from a host of different sources and pasted together. It was common practice in the publishing world of early twentieth-century China for authors and editors of urban presses to draw from their publishers' libraries for sources and engage in the wholesale importation of images, text passages, and recipes when compiling articles. ${ }^{25}$ Producing an article involved cutting and pasting blocks of text with imported images. Editors would then add introductory remarks, or commentary on the images, to give the article a sense of cohesiveness. Some of the pieces under consideration here may have been produced in this manner. For example, in the recipe to make spiritus rosae that appears earlier in this essay, there is no mention of the exact amount of the flower to use, a missing detail that may point to the recipe's piecemeal production. Furthermore, the name of the purported female reader who wrote in demanding more recipes, Mme Xi Meng, sounds very much like a transliteration of a Western name (possibly Simone?), which suggests that the article may have been translated. ${ }^{26}$ The particular manner in which these articles were produced thus poses interesting challenges and opportunities for the historian. Even if we cannot identify a single authorial intent, these pieces nonetheless remain fascinating precisely because of how the modular texts or images were linked together to make a compelling "read." Introductions, prefaces, and other editorial touches reveal the logic of compilation. Thus, translation, appropriation, and local adaptation rather than original authorship of these recipes must be central to our analysis.

\section{THE ARTICLES: HOUSEHOLD TIPS OR MORE?}

Written in an accessible form of classical Chinese, the January 1915 Funü zazhi article, "A Brief Explanation on Methods for Making Cosmetics," was a typical howto piece from a women's magazine. The author, Ling Ruizhu, identified herself as a third-year student at the \#2 Girls School of Jiangsu. The article offered instructions on how to make several different kinds of cosmetics. One entry was for "Soap," identified by the technical Chinese term shijian. The entry reads:

\footnotetext{
${ }^{24}$ Chang Che-chia, "Funü zazhi zhong de "yishi weisheng guwen"” ["Consultation on medicine and hygiene" in the Ladies' Journal], Jindai Zhongguo funü shi yanjiu 12 (December 2004): 145-68, on 153. Since Chang's analysis focuses on the final years of the publication, the journal's reach may have been somewhat differently configured geographically in the earlier years.

25 Wang Fei-hsien, personal communication with Eugenia Lean, 1 December 2008, University of Chicago, Chicago.

${ }^{26} \mathrm{Xi}$ Meng was used as a transliteration for the name of a female English poet, who was introduced in first issue of Nüzi shijie along with other foreign poets. See mention of her in the table of contents of volume 1, issue 1 of Nüzi shijie. As an editor of the journal, Tianxuwosheng no doubt knew of this transliteration.
} 
[Shijian] is commonly referred to as feizao. When it provides a cosmetic function, it is called xiangzao. There is more than one kind. There is cassia-scented soap, zhulanscented soap, ${ }^{27}$ sandalwood soap, etc. For ingredients, one must collect (caustic) soda and cow's fat, pig's fat or coconut oil, etc. Then, add perfume. Its quality depends upon the expensiveness of the perfume, and doesn't have anything to do with the difficulty of making it. ... When you use it, first dissolve the soap in water, and the soda will slightly float apart. Then, you lather it in water and use it to clean your skin or body hair of filth. Its efficacy is remarkable. ${ }^{28}$

Information was imparted in a straightforward, prescriptive tone. Other entries detailed information on making freckle juice, face powder, and perfume.

Upon closer inspection, however, the writings curiously included what was arguably technical information and chemical knowledge superfluous in the actual production process, which belies any characterization that they are merely "practical advice" or "domestic hints." New forms of technology, including modern chemical principles of saponification, the reaction of alkali with fat or oil, both of which are needed to make modern soap, were described explicitly and in detail. Some pieces purposefully highlighted the language and conceptual categories of modern chemistry. Take, for example, the March 1915 article, "Method for Making Rouge":

Rouge is made from the flower petals of the red flower 紅花 (Carthamus tinctorius L. [sic]) and is one of the important items among cosmetics. Red flower is part of the chrysanthemum family.... Its height is around 2-3 chi. Its flower petals contain red and yellow pigment. The red pigment named Karthamin $\left(\mathrm{C}_{14} \mathrm{H}_{16} \mathrm{O}_{7}\right)$ is the main component of rouge. ... When [the petal pigment] comes into contact with an acid type then it precipitates into sedimentation. If you take the dissolved sediment part, then high quality manufacturing is possible. ${ }^{29}$

In explaining the ingredients of rouge, this passage explicitly used scientific terms. Carthamus tinctorius $L$. was the Latin name for safflower used in the Linnaean taxonomic system, referring to the flower needed to make the red dye for rouge. In the original article, the term was written in the Romanized alphabet and thus stood out sharply in the otherwise primarily Chinese text. The Latin term for red dye, Karthamin, was similarly Romanized. So too was the chemical compound, $\mathrm{C}_{14} \mathrm{H}_{16} \mathrm{O}_{7}$. The text also employed the discourse of modern chemistry in describing the rouge-making process. Sodium carbonate (sodium salt of carbonic acid) was specified as the preferred acid-type for precipitating the petal's pigment into sedimentation.

These writings emphasized experimentation, sensory know-how, and bodily engagement. "A Brief Explanation on Methods for Making Cosmetics" was typical in that it featured a high degree of prescriptive technical knowledge in the form of practical advice. The author, Ling Ruizhu, not only displayed expertise in chemistry and manufacturing but also served as a practical advisor, whose "tips" resulted from her own hands-on experience in making and experimenting with things. In the technical explication of manufacturing soap, Ling advised readers that the best way to tell whether the soap was high quality was through one's senses. "With the tip of the tongue, taste it. If there is no peppery, acrid taste, then it is a quality commodity

\footnotetext{
${ }^{27}$ In modern botany, zhulan is Chloranthus spicatus, or makino, a tree with fragrant yellow beadlike seeds.

${ }^{28}$ Ling, "A Brief Explanation” (cit. n. 1), 17-8.

${ }^{29}$ Hui, "Method for Making Rouge" (cit. n. 1), 15.
} 
[shangpin]." 30 This advice, while terse, nonetheless spoke volumes in alluding to a new and practical way of knowing and by promoting ingenuity and inventiveness as virtues. Experiential knowledge and experimentation were valued. Chen Diexian exhorted his readers to experiment with basic ingredients in the January issue of "The Warehouse," the entry with which we started this essay. Technical and scientific information could be obtained from mundane ways of knowing, including hands-on experience, trial and error, and physical engagement with ingredients.

While these writings were more than just "domestic hints," their emphasis on the domestic sought to convince readers of the moral relevance of industry and technology through the trope of the domestic. It was no accident that they promoted the ideal domestic site for chemistry and manufacturing as the well-to-do space of the genteel inner chambers. In his May 1915 contribution to "The Warehouse" column, Chen Diexian, writing under the name Xu Yuan, identifies women's inner chambers as ideal sites for chemical experimentation:

Use [the method for absorption] to make gifts for your friends in the inner chambers ( $g u i$ -
you). It is rather enjoyable. Moreover, you can use seasonal flowers and make different
kinds of solid fragrances; you are not restricted to using rose essence [the only fragrance
available on the market]. The chemical method ... of absorption ... has become the
strategy of experimentation (shiyan ji) in the inner chambers. All you need to do is obtain
some simple tools and follow the [instructions below]. ${ }^{31}$

The inner chambers had become a place where one's senses (in this case, one's olfactory senses) could be deployed as a site for scientific experimentation. In the rest of the article, $\mathrm{Xu}$ described the exact kind of jar to use at home, provided instructions on how to make a copper sheet into a thin tube, and how to place it in the jar, with the precise measurement of how far away from the four sides the tube needed to be. He also provided directions for how to sterilize the jar without cracking the glass and how to use Vaseline and scents to make solid perfumes. The end of the article narrated the exact process by which to calibrate the strength of fragrances in the making of perfume with different kinds of flower petals. Xu concluded by advising, "There is only one matter one must really pay attention to. If the fragrance is too pungent, then the result is not beautiful. Fragrance is like color. If a color is too strong, it appears murky and dark. If a scent is too pungent, it causes unpleasant olfactory senses. If you use less, the scent will unfold and be alluringly fragrant. Thus, those making scents must understand the physics (behind the process)." 32

By identifying the well-to-do space of the inner chambers as the ideal domestic site for chemistry and experimentation, Xu Yuan underscored the exclusivity of such productive practices. These were not the quarters of more modest homes or parlors of modern treaty-port homes. They were the refined inner chambers of elite households. References to gift exchange among genteel women, the seemingly disinterested act of "enjoyment," and an emphasis on "friendship" among like-minded people further evoked the image of literati cultivation long associated with such fine spaces. At the same time, $\mathrm{Xu}$ made sure to present this space as fully modern. The inner chambers did not resemble the traditional literati study, where reflective moral contemplation

${ }^{30}$ Ling, “A Brief Explanation” (cit. n. 1), 18.

${ }^{31}$ Xu Yuan, "Huazhuangpin zhizao ku,"Nüzi shijie 5 (May 1915): 1.

32 Ibid., 2-3. 
took place through the study of texts. Nor were they a space for talented women to embroider, exchange poetry, or participate in a separate "woman's culture." They differed considerably from imperial period households that had been engaged in textile production..$^{33}$ In these early Republic writings, the inner chambers had become a space where things were manufactured through chemical means, a place where experiments abounded and modern production practices could be enjoyed.

$\mathrm{Xu}$ proceeded in one entry to tout domestic production as superior to items available in stores. He writes triumphantly,

Now, in the inner chambers, it is a common practice to take hair tonic as suitable for use. That which is sold on the market is also called hair gel and uses fat. It is sold in small glass bottles or stored in small porcelain boxes. Its weight is no more than an English tael and its selling price is regularly above a silver yuan and two jiao. If you buy the original ingredients and make it yourself, [however], it is far more inexpensive. Try what is explained [below]. . . . You can use it whenever you like, and it is hardly different from what you can buy on the market. [Furthermore] . . . that which you can buy on the market is all made into a rose scent. . . [At home], if you like other kinds of scents, you can use ... other kinds of perfumes and add it into the mixture. ${ }^{34}$

Making an appeal to frugality, Xu promoted the homemade version as the same in quality as the store-bought type, and far less expensive. He stressed how home manufacturing allows for more flexibility and thus the production of more scents. He then warned that store-bought fragrances ran the risk of being "infected with dirt" as they were mixed with different kinds of inferior fat. Household production was heralded as superior to market consumption.

To underscore the relevance and urgency of this technical know-how, these writings not only gendered the know-how but also invoked several powerful moral discourses. The classical belief in the importance of the household management of womanly virtue and production for the larger polity is, for example, an important concept for grasping the significance of the Funü zazhi article, "The Method for Producing Cosmetics." 35 Its author, a Mme Shen Ruiqing, declared that women's knowledge of how to make cosmetics, and thus the ability to truly know their nature, was at the crux of improving the state of the household (jiating). She began with a warning: "Cosmetics are things [pin] that women need. Their price is rather expensive. When women are being thrifty, cosmetics count as a kind of expendable item. Is it better then not to use them?" To answer the question, Mme Shen invoked the traditional belief that women's proper appearance and deportment was one of four womanly virtues. "Having balding hair and not treating it, and having teeth plaque and not cleaning it, all obstruct the hygienic welfare of the household [jiating weisheng] . . if we use [cosmetics] without knowing their nature [pinxing], this is lacking in household knowledge [jiating zhishi]." By placing such a premium on household order, Mme Shen strongly evoked the classical Neo-Confucian [lixue] discourse that linked the harmony of the domestic feminized realm [nei] with the moral harmony of the masculinized outer [wai] realm

${ }^{33}$ With the imperial-era discourse of "men till and women weave" [nangeng nüzhi] identifying female production of cloth as the crux of a productive empire, women of all classes actively engaged in their homes in the "womanly work" of weaving, textile making, and managing the household production of things. See Bray, Technology and Gender (cit. n. 12), esp. pt. 2.

${ }^{34} \mathrm{Xu}$, "Huazhuangpin zhizao ku" (cit. n. 31), 1.

35 Shen, "Method for Manufacturing Cosmetics" (cit. n. 1), 18-25. 
of political cosmology. Family relations had metaphorical implications for political relations; wifely chastity and filial piety were metaphors for political loyalty. If men's pursuit of textual knowledge had tended to exclude them from the realm of practical manual labor, women's work in the household was deemed crucial for a productive state of affairs beyond the domestic domain.

In identifying the production of women's things to be the crux of household harmony and emphasizing knowing the nature of objects through their production, the Funü zazhi article also resonated strongly with the imperial discourse on gewu zhizhi, the "investigation of things" (abbreviated hereafter as gewu). The philosophical discourse on gewu was primarily seen as an act of textual classification rather than an actual engagement with material objects. As the subject of broad learning [bowu], the concept of things $[w u]$ in gewu was defined expansively, referring to "objects, events, mental and physical phenomena, the unknown, and the anomalous." 36 As such, things were to be known, or decoded, through the words and language of philosophers and connoisseurs. Accordingly, gewu practitioners expended a great deal of textual energy etymologizing the world and life of things to probe universal principles and seek the moral harmony of the larger sociopolitical cosmos. ${ }^{37}$ As the classical Confucian text "The Great Learning" [Daxue] explained, it was by grasping the nature of things that individuals could complete their knowledge, and by extension, that an imperial state could achieve its harmony. ${ }^{38}$

By taking as its basic premise that obtaining knowledge (especially textual knowledge) of material things such as women's cosmetics and toiletry items will result in moral harmony, this Funü zazhi article appeared to be drawing on the tradition of gewu. For Mme Shen, full understanding of women's objects (in part, achieved through textual study of her article) was the key to cultivating household harmony. Vanishing face cream and hair grease were presented as at once necessary and potentially destabilizing. They helped women uphold the virtue of appearance and deportment and yet were fraught with potential danger. If their nature was not understood properly, they could potentially lead women and, by extension, the household to dissolute, wasteful consumption. The piece thus provided a prescription against a scenario of household dissolution by detailing production know-how and the proper understanding of the nature of such things. The rest of the article recounted the chemical makeup of different cosmetic items, and how to manufacture and properly use them. It included a list of original chemical ingredients in the section on the "dissection of [the item's] various parts," the manufacturing method [zhifa], the method for using the item [yongfa], and supplementary notes that included a warning about how to handle the glycerin properly when making lotion that removes freckles. ${ }^{39}$ Readers

\footnotetext{
${ }^{36}$ Benjamin Elman, On Their Own Terms: Science in China, 1550-1900 (Cambridge, Mass., 2005), xxix.

${ }^{37}$ For more on the rich and complex history of the discourse of gezhi in imperial China, see ibid.

${ }^{38}$ Daxue was one of the four canonical Confucian classics, institutionalized in the Song dynasty as part of the civil service examination curriculum. Originally part of the Book of the Rites, Daxue was authored by Confucius (551-479 BCE) in the sixth century BCE.

${ }^{39}$ Glycerin is a neutral, colorless, thick liquid that freezes to a gummy paste and has a high boiling point. It can be dissolved into water or alcohol, but not oils. Since many things will dissolve into glycerin more easily than they do into water or alcohol, it functions well as a solvent. Soap fats already contain glycerin, and it is when the fats and lye interact in the formation of soap that glycerin is left out as the "by-product." The above warning about handling glycerin is probably because glycerin is often
} 
also learned how to make hair dye, face powder, l'eau de toilette, liquid rose rouge, face lotion, perfume glycerin, toilet powder, lavender water, hair tonic, pimple caustic, rose-scented hair grease, lavender-scented hair tonic, camphor tooth powder, and "Hazeline Snow" vanishing face cream. ${ }^{40}$

While the relationship between the moral and the material might not have been new, what was unprecedented was the crucial subtext behind the 1915 interest in the material nature of "women's things." In a postimperial order, modern China had moved away from a Confucian cosmology to become - at least in principle - a Republican nation-state competing in the international arena of capitalism. The focus in these articles on broadening the knowledge of the constituency of certain commodities was meant to ensure China's ability to manufacture goods and its success in this global realm of commerce, rather than harmonize a Confucian social order, despite their palpable concern with China's increasingly commercialized society. The rise of global capitalism in the nineteenth century had resulted in Chinese markets being flooded with foreign commodities [pin 品], ranging from opium to industrial goods. The humiliating military defeats by Western powers and modernized Meiji Japan seemed to confirm China's technological and material inferiority. This anxiety ensured that materiality loomed large in these articles and notably often in a language that arose from the context of international trade.

The choice of toiletry items, such as soap and hair tonic, was moreover hardly accidental or frivolous. As Mme Shen's reference to the need for a hygienic welfare of the household suggests, the international discourse of China's deficiency in hygiene and health conditions that had gained currency by the latter part of the nineteenth century cast a large shadow in these pieces and was invariably linked to the perception that China's weakened state led to increasingly aggressive and violent imperialist subjugation. Chinese intellectuals, reformists, and administrators quickly internalized this discourse. The need to modernize the "sick man of Asia" implied that the Chinese body had to be made anew into a clean and healthy one. Reformists and intellectuals were thus actively promoting new regimes of "hygienic modernity" in the reformist press, through anti-foot-binding associations, and in the creation of physical education curricula and institutions. ${ }^{41}$ The Funü zazhi and Nüzi shijie writers allied themselves to this cause by calling for the hygienic welfare of the household and were charged with a political and moral imperative. The focus on the production of these objects served to contain the object of cosmetics from a potentially dangerous consumerist attraction into something that would make the nation strong.

Concern with China's manufacturing competitiveness was also apparent in the article, "Method for Making Rouge":

Our country's rouge has been long famous. But as a beauty product of the (traditional) inner chambers, [our rouge] has had no significance for the fate of the nation and the lives of citizens. However, if we acquire the (proper) methods, we can manufacture it

used to make nitroglycerin. But this warning may in fact be moot since glycerin is not an explosive substance by itself and has to be turned into nitroglycerin before it becomes explosive.

${ }^{40}$ Hazeline Snow was a British brand and one of the most popular vanishing face creams marketed in China's treaty ports at the time.

${ }^{41}$ For more on "hygienic modernity" in China's treaty ports, such as Tianjin, see Rogaski, Hygienic Modernity (cit. n. 11). 
[like] recent imports, including the so-called foreign rouge. . . [Indeed] without quality manufacturing techniques [zhizao jingqiao], how could these [foreign] countries have robbed us of our power? Thus, with the production technique I describe below, I speak to my comrades in the women's world and contribute for all to examine and study; with this production technique, we can obtain true mastery!42

In this passage, the potential wealth of the nation was directly linked to technical expertise and proper knowledge. The segment also illustrates the metaphorical quality of the "woman's world" and the domestic sphere. The author identified products of the old inner chambers as being dangerously outdated, and because of their lack of relevance for the polity, a potential hazard to the fate of the nation. An appeal is made for the author's "comrades in the woman's world" to take seriously the competitive new production techniques outlined in the article. The urgent plea to improve methods of manufacturing was meant not only for actual housewives. "Comrades in the women's world" referred to new-style lettered and entrepreneurial elites, including men. By engaging in chemistry, experimentation, and production (whether through the production or consumption of these writings, or in actual practice), participants in this discourse could articulate an unprecedented urban identity that turned on a newfound zeal to reform the nation through commerce and manufacturing.

In short, these writings adapted a variety of strategies to legitimate the chemical and manufacturing knowledge they were promoting to China's urban readers. By identifying the feminized inner chambers as the spatial site of scientific activity, these pieces wove together a moral discourse defining virtuous production as relevant and necessary for the new age. Columns like "The Warehouse" rendered ideal reader-producers like Mme Xi Meng as exemplars, who embodied new forms of technical knowledge and scientific production to which both male and female readers would ideally aspire. The pieces also mobilized an array of moral discourses. The classical Neo-Confucian discourse on the management of the household served to establish that the activities described on these pages had implications beyond the domestic arena. The gewu legacy shaped the emphasis placed on the need to know thoroughly the nature of things, including soap and cosmetics. And, the late nineteenth-century imperialist discourses on hygiene made the writings relevant to the contemporary world where China's national fate was at stake. Taken together, the message delivered by these pieces was clear. Productive self-sufficiency in the feminine domain of the inner chambers was to be both a metaphor for and a means to material self-sufficiency for China. Such writings were part of a larger contemporary discourse on virtuous women's work [nügong] that filled the pages of women's journals such as Funü zazhi, discussed by Constance Orliski. Yet, whereas Orliski argues that this broader discourse engaged specifically in the construction of middle-class ideals of productive women, I argue that the feminized discourse of production examined here was just as much about the construction of new norms of masculinity. ${ }^{43}$ As we see next, these writings-despite being gendered feminine-were sources of inspiration and concrete information for male dabblers in chemistry, budding manufacturers, editors and authors of domestic science columns, and leisurely connoisseurs of technology.

\footnotetext{
${ }^{42}$ Hui, "Method for Making Rouge" (cit. n. 1), 15.

${ }^{43}$ Constance Orliski, "The Bourgeois Housewife as Laborer in Late Qing and Early Republican Shanghai," Nan Nü 5 (2003): 43-68.
} 


\section{AMATEUR SCIENTISTS AND WOULD-BE INDUSTRIALISTS}

Editors, authors, and readers of these pieces included connoisseurs of chemistrymen and women - as well as male would-be industrialists and amateur science experimenters. All were invested in advancing domestic chemical production and the industriousness of the virtuous guixiu as a means to disseminate and endorse the practical information and chemical know-how provided in these recipes as a legitimate source of male knowledge and endeavors. The early twentieth century saw the flourishing of light industry and manufacturing in China. While a stable and mature industry may not have existed until the Nanjing decade (1927-37), ${ }^{44}$ Chinese companies had started to open soap and cosmetic factories as early as the first decade of the twentieth century. One of the earliest domestic soap factories, the Nanyang Soap and Candle Factory of Jiangsu Province, was established in 1910.45 Another early cosmetic company was the China Chemical Industries Company, which was established in 1911 and whose founder, Fang Yexian, I discuss below. ${ }^{46}$ By 1915, the Ministry of Agriculture and Commerce established in Beijing the Bureau of Industrial Research, which was dedicated to the analysis of native products, including cosmetics and dyes, and played a crucial role in promoting and building native industry. ${ }^{47} \mathrm{~A}$ number of cosmetic and pharmaceutical companies were founded soon thereafter. In 1917, two years after his tenure as the editor of the Nüzi shijie and its "Warehouse" column, Chen Diexian himself established the pharmaceutical company Household Industries, with $\$ 10,000$ of capital he had earned from his fiction and editing work. ${ }^{48}$ The most popular product produced by Household Industries was Chen's own invention, the "Butterfly" brand (Wudipai) tooth powder that could double as face powder. ${ }^{49}$

In this context, it is not difficult to imagine how would-be industrialists might have turned to these 1915 recipes for inspiration, if not actual manufacturing tips. A strong political undercurrent that would appeal to such readers regarding the need to domesticate production not just literally, but figuratively, can be found in the content of

44 James Reardon-Anderson attributes this to the Nationalists for providing enough direct investment in research and industry, a degree of political and social stability, as well as a dose of benign neglect. See Reardon-Anderson, The Study of Change (cit. n. 17).

${ }^{45}$ For more information on this company, see Zhongguo guohuo gongchang shilue [A historical sketch of China's national product factories] (Shanghai, 1935), 23-4.

${ }^{46}$ For more on this company, see ibid., 63-4. See also China Industrial Handbooks Kiangsu (Shanghai, 1933), 507-11.

${ }^{47}$ In the late Qing under the New Policies reforms, Yuan Shikai had established a similar bureau in Zhili, known as the Bureau of Industry, which lasted from 1903 to 1907 and was meant to develop modern industry in the Zhili region. It established a higher education facility in industry, organized displays, ran workshops, lectures, and night classes to teach trade and industry, printed educational materials, and visited factories to encourage and develop industry. For this information and more, see the Bureau's 1907 gazetteer, Zhili gongyi zhi chubian [Zhili industrial gazetteer], 1st ed. For histories on the role of government-national and regional-in developing industry, see relevant sections in Yutang Sun, Zhongguo jindai gongshi ziliao [Source materials on the history of industry in modern China] (Beijing, 1957), and Jun Gong, Zhongguo xin gongye fazhang shi dagang [The historical synopsis of the development of new industry in China] (Shanghai, 1935).

${ }^{48}$ For more information on this company, see Zhongguo guohuo gongchang shilue (cit. n. 45), 23-4, 117-8, and 127-8. See also China Industrial Handbooks Kiangsu (cit. n. 46), 508.

${ }^{49}$ The official English name of the tooth powder was "Butterfly," which was a translation of the Shanghaiese pronunciation of the Chinese name of the product, Wudi. However, the name brand when read or pronounced in Mandarin connoted another meaning. The compound wudi literally means "peerless," or "without enemies," and Wudipai means "Peerless Brand." In the context of the National Products Movement, of which Chen was a leader, the name thus gained great significance. 
several pieces. In "Method for Producing Cosmetic Soap with Care," Kuang Yu, the author of an article in the March 1915 "Warehouse" column of Nüzi shijie, wrote,

High-quality soap can ... make the skin smooth and glossy (like jade). Thus, among cosmetic products, soap occupies an important place. Today, our countrymen establish factories to manufacture soap and attend to its production. Generally, most of the products are inferior. One reason is because the original ingredients are poor quality. Another reason is that the manufacturing method is not ideal. We cannot be surprised that the soap used in our inner chambers cannot compete with imported products. Trace the cause of this ... not to a thorough enjoyment of using foreign products [per se], but to the fact that in our country there are no good products. ${ }^{50}$

Included in a column dedicated primarily to domestic production, this piece is notable for its abiding concern with China's fledgling manufacturing industry and its inferior products. As if retorting to critics who might say that it is the fault of consumers who enjoy using imports, the passage underscored that it was not lavish attachment to foreign items, but rather substandard production of domestic products that was at fault. Moreover, the reference to inner chambers in the piece speaks to the metaphorical meaning of the domestic trope in which to bolster the products of the inner chambers was to improve the industrial strength and competitiveness of China. In an era when patriotic consumption and production were gaining traction in campaigns such as the National Product Movement, such writings resonated with patriotic readers, some of whom certainly included actual or would-be manufacturers. ${ }^{51}$

The rest of the article offered concrete tips and manufacturing methods to improve China's ability to compete internationally.

To make this, you first need to take 1,000 liang of high-quality cow fat (you can also use the highest quality olive oil), throw it into a cauldron, and melt it until the fat is completely dissolved. Then, take 150 liang of high-quality caustic soda, and dissolve it into clear water until it becomes a thin liquid. ... When adding the caustic soda, you must use a wooden paddle and stir without stopping. After cooking it to the point of boiling for approximately 4 hours, the caustic soda and the cow fat will have thoroughly combined. That which floats on top is pure white, fine and delicate soap paste. . . Choose the best fragrance ... add it in; thoroughly mix ... pour it into a mold, and ... an exquisitely fragrant colored soap results. ${ }^{52}$

Where the piece merits particular attention is its mention of 1,000 liang of highquality cow fat, which is around 83.33 pounds of cow fat, a considerable amount that would produce a large amount of soap. ${ }^{53}$ This recipe was clearly not intended for mere household production, but for large-scale manufacturing.

Biographies reveal that would-be manufacturers and dabblers in chemistry were indeed active participants in this discourse. First and foremost is Chen Diexian, the

\footnotetext{
${ }^{50}$ Kuang Yu, "Huazhuangpin zhizao ku,” Nüzi shijie 3 (March 1915): 3.

${ }^{51}$ For more on China's early twentieth-century National Product Movement, see Karl Gerth, China Made: Consumer Culture and the Creation of the Nation (Cambridge, Mass., 2003).

52 Kuang, "Huazhuangpin zhizao ku" (cit. n. 50), 3.

53 According to a "Chinese Weights and Measures Table" published in the "Chinese Maritime Customs, 1922-1931 Decennial Reports," a liang is a tael, and sixteen liang is equivalent to one jin (catty), and 1,000 liang would be around 62.5 jin. With 100 jin (catties) the equivalent of 133.33 pounds, 62.5 jin would be around 83.33 pounds.
} 
editor of the how-to column of the Nüzi shijie that we are examining here. His biographical accounts portray him as an amateur chemist who turned his literati studio into a chemistry lab in his early years in Hangzhou. ${ }^{54}$ He also opened a shop to sell books and imported scientific instruments and appliances, as well as a public librarycum-reading room, which featured translated scientific texts. In early 1913, while serving in a staff post in Zhenhai, a city on the Zhejiang coast near Ningbo, Chen spent his days experimenting with cuttlefish and coastal brine to locally source calcium and magnesium carbonate, key ingredients in tooth powder. The result of his experiments was the above-mentioned versatile tooth powder that could double as face powder. It was with this dual-functioning tooth powder, along with proceeds he made from being a professional writer and editor in Shanghai, that Chen went on to found Household Industries, which became a leading domestic pharmaceutical company that competed with major international companies for market share in urban China's competitive hygiene and cosmetic market. As an industrial captain, powerful Shanghai editor, and advocate for manufacturing know-how, Chen was a key participant in using the new genres of women's journals to promote new forms of knowledge that could serve as the foundation of the new masculine ideal of serving the nation through industry.

While we cannot be sure he read these exact pieces, Fang Yexian (1893-1940), the above-mentioned cofounder of one of Republican China's most successful light chemical industry companies, China Chemical Industries Company (hereafter, China Chemical), read similar material to procure the knowledge necessary for his manufacturing endeavors. Born in Shanghai into a business family (family enterprises included banking houses, pawn shops, jewelry shops, and sundry goods stores), ${ }^{55}$ Fang was sent to the Anglo-Chinese College, a missionary educational facility founded in 1882 in Shanghai, where he developed a particular interest in chemistry. There he studied with a German chemistry instructor who had been hired by the Shanghai Municipal Council of the International Settlement. ${ }^{56} \mathrm{He}$ pursued his interests outside of the classroom, too, by taking advantage of the late nineteenth-century missionaryrelated network of public science and reading rooms. He avidly consumed journalistic writings of precisely the sort considered here, along with specialized books, to create a household laboratory, engage in chemical experiments, and make everyday items such as cosmetics at home. As a result of such activities, Fang founded China Chemical with his mother's support in 1912 (his father was against the enterprise). It started with a few individuals and disciples but in twenty years became the leading Chinese manufacturer of tooth powder, with one of its most popular items being the Sanxing brand tooth powder. The company was also successful in manufacturing food-flavoring powder, including the Boddhisattva powder (Guanyin fen), and Jiandao soap. Later,

\footnotetext{
${ }^{54}$ For biographical information on Chen Diexian, see Chen Dingshan, "Wode fuqin TianxuwoshengGuohuo zhi yinzhe" [My father, Tianxuwosheng - recluse of the National Products (Movement)], in Chun Shen jiuwen (Taipei, 1967), 180-204; and Chen Xiaocui, Fan Yinqiao, and Zhou Shoujuan, "Tianxuwosheng yu Wudipai yafen" [Tianxuwosheng and Wudipai tooth powder], in Wenshi Ziliao Selections, ed. Zhongguo renmin zhengzhi xiehuiyi quanguo weiyuanhui wenshi ziliao yanjiu weiyuanhui [The National Association of the Chinese People's Political Society's Association for the Research of Historical and Literary Materials], vol. 80 (Beijing, 1982).

${ }^{55}$ For biographical information on Fang Yiexian, see, e.g., Pan Junxiang, ed., Zhongguo Jindai Guohuo Yundong [China's modern National Products Movement] (Beijing, 1996).

56 The Chinese name of the instructor was Dou Bolie, most likely a rendition of the German name.
} 
Fang became known as the King of National Products because of his anti-Japanese activism in the National Products Movement. ${ }^{57}$

As Chen's and Fang's biographies indicate, young men often dabbled in science in informal spaces and venues at the turn of the century. Some of these amateur scientists went on to build successful careers in the industry. Others, however, did not have the financial support to be able to start their own pharmaceutical empires or build industries but found other uses for such formulas and recipes. A colorful example is the famous Daoist practitioner Chen Yingning (1880-1969). Like Fang, Chen was an amateur scientist who practiced in informal settings and among literati friends and collaborators. He built a home laboratory to engage in chemical experimentation in pursuit of Daoist goals of longevity through external alchemy. As Xun Liu details in his study of modern Daoism in urban Shanghai, Chen's pursuit of domestic experiments was a team effort. ${ }^{58}$ Chen's wife, a modern gynecologist, and four other fellow practitioners of alchemic self-cultivation, financed the endeavor. Located near the entertainment center of the Yu Garden, Chen's urban home set aside two rooms for his experiments, most of which involved smelting metals in attempts to test the veracity of secret formulas from ancient alchemical recipes. His laboratory was stocked with key alchemical minerals such as cinnabar, mercury, silver, and lead and was equipped with heating furnaces and refining crucibles. He would invite friends to his laboratory, perform experiments in front of them, and discuss for hours into the night various formulas and their efficacy for self-cultivation. Xun Liu suggests as well that this group, many of whom were doctors, scientists, and scholars educated abroad or in modern universities in China, were exposed to popular science journals featuring how-to pieces similar to the ones under consideration here and that their alchemical experiments were clearly informed by modern chemistry.

While the Fang Yexians and Chen Yingnings of the world provide profiles of potential male participants in this discourse, it is entirely possible that women participated for similar reasons. Actual examples are hard to come by, but Wu Yizhu (1882-1945), Chen Yingning's wife, is the kind of woman who might have put these writings to use. Wu was one of several new-style women who took advantage of the array of new ideas and opportunities available in treaty ports and in the urban press, along with their male counterparts. She was a well-educated female who traveled in the circles of these new urban elites. In addition to having trained at the Sino-Occidental Medical College, she became a successful modern gynecologist and was an active participant in building modern Daoist circles and supporting, if not actively engaging in, the domestic chemical experimentation integral to Daoist pursuits of self-cultivation. ${ }^{59}$

From these biographies, we can see how these articles were part of a larger exploration of manufacturing and chemistry that was being pursued in a variety of settings. This was a moment before the professionalization of industry and science in China,

\footnotetext{
${ }^{57}$ It was this same activism and his unwillingness to work in collaboration with the pro-Japanese Wang Jingwei government that finally led to Fang's assassination by secret agents in 1940. For an English-language account of his involvement in the National Products Movement, see Gerth, China Made (cit. n. 51), esp. 180-1.

58 Xun Liu, Daoist Modern: Innovation, Lay Practice and the Community of Inner Alchemy in Republican Shanghai (Cambridge, Mass., 2009), 71, 299n68. Liu suggests that they were most likely aware of contemporaneous attempts by Sinologists and historians of science in the West and Japan to link Daoist alchemy to the origins and history of modern chemistry, by viewing Daoist alchemic experiments as iatrochemistry, the forerunner to modern chemistry.

${ }^{59}$ For more on Wu Yizhu, see ibid., 56-8.
} 
which would function to discipline and draw boundaries around associated activities and knowledge, locating them, for example, in formal sites such as the university, the science lab, or the modern factory. The 1910s saw practices associated with modern science, including experimentation, observation, building laboratories, and using modern scientific equipment, often taking place in the home, in literati studios, and in storefronts. While textbooks and technological compendia were sources for technical information and modern science, so too were missionary reading rooms, science displays, and how-to writings in the women's press. Chemistry was pursued out of a variety of motives, whether to increase manufacturing, for leisurely connoisseurship, or as part of other cultural pursuits, such as updating Daoism for the modern age.

\section{CONCLUSION}

By 1915, the promises of the 1911 revolution seemed increasingly undeliverable, and Western imperialists and Japan continued to compromise Chinese sovereignty, humiliating China internationally and persisting with invasive forms of extraterritoriality. In the greater Shanghai and Guangdong areas, where women's journals were widely circulated, more commercially oriented elites readily disengaged from the political scene. The "domestic hints" literature examined here provided these disenfranchised editors and authors the opportunity to appropriate the domestic realm to define an alternative site of elite moral activity. The household was redefined as a feminine site where chemistry and manufacturing were to be enjoyed and exalted above mass manufacturing and the crass market. As avid participants in this discourse, male writers and authors appropriated the feminine to explore new forms of knowledge and endeavors. The domestic and, indeed, the feminine itself became metaphors for the productivity of a commercial and scientific culture that thrived, in contrast to the (masculine) political arena, where the failure to establish the republic and build a new nation was all too painfully obvious.

The domestication of manufacturing knowledge in these recipes resonated with the burgeoning National Products Movement and eventually acquired the meaning of domesticating foreign technology for purposes of increasing native manufacturing and strengthening the nation. This movement had already started with boycotts of American goods starting in 1905. By the 1910s, Chinese patriotic sentiment had only deepened and turned against the Japanese in particular. Having declared war on Germany in 1914, Japan followed up not by participating substantively in the European theater but by attacking Germany's concession in Shandong, China. This served as a pretext for Japan to issue a humiliating set of demands, better known as the TwentyOne Demands, to the Chinese government. It was at this point that figures like Chen Diexian became politicized. As biographical accounts later noted, his animus toward the Japanese had been key in motivating him to found his company, Household Industries, in 1918 and develop his Wudipai (Peerless) brand tooth powder to defeat Japan in the market place. ${ }^{60}$ Chen went on to become a leading National Products Movement leader, promoting virtuous copying of foreign technology for the purpose of establishing China's manufacturing autonomy. The 1915 recipes featuring female producers in the inner chambers — some of which Chen compiled - set the stage for

${ }^{60}$ See, e.g., Chen, "Wode fuqin Tianxuwosheng," 184, and Chen, Fan, and Zhou, "Tianxuwosheng yu Wudipai yafen,” 217-8 (both cit. n. 54). 
anti-imperialist activities and patriotic manufacturing that served as alternative ways for men to serve the country.

In only a few years, the promotion of "Mr. Science" by Beijing-based intellectuals would substantially challenge the gendered portrayal of technology found in the 1915 how-to pieces, as well as the politics of such knowledge. In 1919 in what is now known as the May Fourth Movement, students and citizens of Beijing marched to protest China's humiliating treatment in the signing of the Versailles Treaty and called for the need to strengthen the Chinese nation domestically against warlords and internationally against imperialists. Central to the goals of the movement's participants was the rejection of old ways and the introduction of "new culture," including Western science and political philosophies, which intellectuals had begun to explore and promote during the New Culture Movement (ca. 1915-9). In a New Youth essay published in January 1919, Chen Duxiu, the dean of Peking University and a key leader of the New Culture Movement, promoted "Mr. Science," along with "Mr. Democracy," as the antidote to the superstition of the past and the oppressive shackles of Confucianism and traditionalism. ${ }^{61}$ Adopted by May Fourth activists as a slogan, "Mr. Democracy and Mr. Science" were soon consecrated as essential parts of China's modernity. Through these icons, cosmopolitan intellectuals associated with the iconoclastic New Culture movement sought to claim ownership over "science" and define its purpose in society, as well as define proper norms of elite masculinity. They ardently argued that men truly concerned with China's national fate had to engage in "modern science" [kexue] for nation-state building purposes and the pursuit of modernity. The earlier depictions of manufacturing and chemistry as activities to be pursued leisurely and for enjoyment in the inner chambers by genteel women quickly came to be seen as illegitimate and frivolous.

Historians of China have internalized this canonical May Fourth narrative that "masculine" science deserves attention rather than "feminine" domestic know-how. Accordingly, much attention has been paid to how state-sponsored and "formal" science in modern China developed in direct response to modern China's political plight. Scholarship has tended to focus on the earlier self-strengthening arsenals built by the Qing state, and the founding of formal academic scientific fields like geography and archaeology that occurred in the early twentieth century. ${ }^{62}$ What has not yet been considered, however, is how China's national plight spurred exploration of industry, chemistry, and manufacturing in seemingly apolitical and inconsequential spaces such as China's burgeoning consumer culture and its women's magazines. Not surprisingly, the writings explored here have tended to be either completely overlooked or treated too modestly in the past, misleadingly referred to as "domestic hints" or mere "practical knowledge" for housewives. To remedy such omissions, this essay takes these how-to writings seriously. We have seen how politics formed a crucial undercurrent in these women's press pieces and how these recipes helped legitimate new knowledge,

\footnotetext{
${ }^{61}$ Chen Duxiu, "Xin qingnian zui' an zhi dabianshu" [New Youth's reply to charges against the magazine], Xin Qingnian [New Youth] 6 (15 January 1919): 10-1.

62 For recent work on the arsenals, see Yue Meng, "Hybrid Science versus Modernity: The Practice of the Jiangnan Arsenal, 1864-1897," EASTM 16 (1999): 13-52, and Elman, On Their Own Terms (cit. n. 36). For scholarship on the formation of modern geology, see Shen, Unearthing the Nation (cit. n. 18), and for archeology, Fa-ti Fan, "Circulating Material Objects: The International Controversy over Antiquities and Fossils in Twentieth-Century China," in The Circulation of Knowledge between Britain, India and China: the Early Modern World to the Twentieth Century, ed. Bernard Lightman, Gordon McQuat, and Larry Stewart (Leiden, 2013), 209-36.
} 
shape urban male identity and taste, as well as sow the seeds for elite male activity in manufacturing and production in the early part of the twentieth century.

Rather than the more familiar story that emerges from studies focused on the West, where masculine norms are mobilized to legitimate the production of knowledge about technology or science, we have seen here how feminine ideals served to authenticate industrial and manufacturing know-how in China's burgeoning consumer culture in 1915. Indeed, paying attention to these Chinese recipes raises questions about the way scholarship in the history of science has thought about the relationship between modern science and technology and masculinity. Philosophers of science have powerfully challenged the ideal that science is "pure" and "objective" knowledge, while feminist theorists identified the processes by which women have been systematically excluded from the domain of modern science. ${ }^{63}$ Historical case studies based on examples from the West have tended to follow suit by illuminating the process by which women have been excluded from the domains of science and technology. To challenge essentialist assumptions of science and technology as inherently male endeavors, many have sought to historicize the process by which science and technology have been gendered masculine. ${ }^{64}$ Pioneering and rich as these studies are, a global perspective helps complicate the picture. Not simply a curious exception to the rule, 1915 China serves to remind us that as actors in different societies mobilized gender to legitimate the authority of scientific and technological fields and knowledge, they drew from a wide variety of histories of gendering knowledge and practice. Indicative of a broader epistemological reordering of elite knowledge taking place in the 1910s for both men and women, these writings deployed feminine tropes to ensure that chemistry and manufacturing were appealing and desirable to a group of new urban readers. The "genteel woman's" voice rather than any masculine trope proved most conducive to help articulate the contours of masculinity and make these recipes for the manufacturing of new men in early twentieth-century China so potent.

${ }^{63}$ See, e.g., Evelyn Fox Keller, Reflections on Gender and Science (New Haven, Conn., 1985); and Sandra Harding, The Science Question in Feminism (Ithaca, N.Y., 1986).

${ }^{64}$ Classic examples include Robert A. Nye, "Medicine and Science as Masculine 'Fields of Honor,", Osiris 12 (1997): 60-79; Ruth Oldenziel, Making Technology Masculine: Men, Women, and Modern Machines in America, 1870-1945 (Amsterdam, 1999). 